\title{
Application of the Complementarities of Two Theories, APOS and OSA, for the Analysis of the University Students' Understanding on the Graph of the Function and its Derivative
}

\author{
Vahid Borji ${ }^{1 *}$, Vicenç Font ${ }^{2}$, Hassan Alamolhodaei ${ }^{1}$, Alicia Sánchez ${ }^{2}$ \\ ${ }^{1}$ Ferdowsi University of Mashhad, Mashhad, IRAN \\ 2 University of Barcelona, Barcelona, SPAIN
}

Received 3 November 2017 - Revised 20 February 2018 - Accepted 12 March 2018

\begin{abstract}
The goal of this paper is the combined use of two theories, APOS and OSA, for the analysis of the university students' understanding on the graph of the function and its derivative. For this, we study the students' understanding to solve one graphing problem in relation to the first derivative and characterize their schemas in terms of levels (intra, inter and trans) of development of the schema for sketching $f^{\prime}$ when given the graph $f$. We present a multiple case study in which 14 students of the first course of Calculus in one university of Iran participated voluntarily. Results show that most of the students in our study had major problems in developing mental constructions and doing the practical work needed to solve the problem, particularly those mental constructions that have to be made to calculate the derivative at the critical points and to determine the speed of the variation of the inclination of the tangent lines to $f$, which is why most of them have constructed a schema at the intra level of development of the schema for sketching $f^{\prime}$ when given the graph $f$. We finish with some final conclusions.
\end{abstract}

Keywords: students' graphical understanding, the concept of derivative, APOS theory, OSA theory, mathematical object

\section{INTRODUCTION}

In Iran, teaching of Calculus in the first courses of university is usually based on textbooks that place the emphasis on algebraic representations and disregard graphical representation (Borji \& Alamolhodaei, 2016a, 2016b). This is a phenomenon that also occurs in other countries (Park, 2015; Sánchez-Matamoros, García \& Llinares, 2008). For this reason, most of the students can solve a routine differentiation problem easily but have no correct conceptual understanding of derivative's graphical representation and the correlation between the algebraic and graphical representation (Baker, Cooley, \& Trigueros, 2000). For instance, some of the students or even teachers do not know the correlation between the slope of the tangent line and difference quotient $\operatorname{limit}\left(\lim _{x \rightarrow a} \frac{f(x)-f(a)}{x-a}\right)$ (Badillo, Azcárate, \& Font, 2011; Özmantar, Akkoç, Bingölbali, Demir, \& Ergene, 2010; Sahin, Erbas, \& Yenmez, 2015; SánchezMatamoros, Fernández, \& Llinares, 2015).

Recent research papers (Badillo et al., 2011; Drijvers, Godino, Font, \& Trouche, 2013; Font, Trigueros, Badillo, \& Rubio, 2016; Fuentealba, Sánchez-Matamoros, Badillo, \& Trigueros, 2017; Mackie, \& Court, 2002; Pino-Fan, Godino \& Font, 2011; Pino-Fan, Font, Gordillo, Larios, \& Breda, 2017; Robles, Telechea \& Font, 2014; Tall, 2013; Tiwari, 2007) on learning and teaching of Calculus have revealed the complexity of the fundamental mathematical objects in this area of mathematics (derivative, integral, etc.) and the need to teach different partial meanings of these objects and connect them to each other for their understanding. In order to do this, the use of different representations and translations between them is fundamental (Font, 2000). One of the approaches that try to characterize this complexity is the APOS theory. In the APOS (Fuentealba et al., 2017) the type of understanding that allows to relate different partial meanings of a mathematical object is characterized in terms of thematization of schema and in

(C) 2018 by the authors; licensee Modestum Ltd., UK. This article is an open access article distributed under the terms and conditions of the Creative Commons Attribution License (http://creativecommons.org/licenses/by/4.0/).

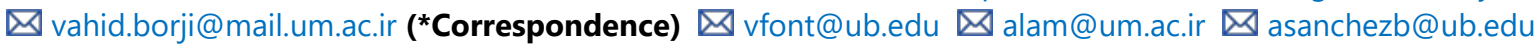




\section{Contribution of this paper to the literature}

- Our goal in this study is to investigate, in terms of levels (intra, inter and trans) of development of the schema, students' understanding to solve a problem, where the graph of a function includes some critical points, and it asks to draw the graph of $f^{\prime}$.

- To achieve this goal, the use of APOS is complemented by the OSA theoretical tools to better characterize the mathematical activity performed by the student and to be able to infer their understanding of the problem.

- The results show that most of the students in our study had major problems in developing mental constructions and performing the practical work needed to calculate the derivative at the critical points.

terms of levels (intra, inter and trans) of development of this schema. For this reason and given that there is little research on this topic at international level, particularly in Iran, our goal is to investigate students' understanding to solve one problem, where the graph of a function includes some critical points and it asks to draw the graph of $f^{\prime}$, and we characterize students' schema in terms of levels (intra, inter and trans) of development of the schema for sketching $f^{\prime}$ when given the graph $f$. To achieve this goal, in this paper the way of understanding APOS comprehension is complemented by the use of OSA theoretical tools to better characterize the mathematical activity performed by the student and to be able to infer their understanding of the problem. The use of tools of OSA is incorporated because we consider, according to Font et al. (2016), that a networking of APOS and OSA provides tools to explain the difficulties associated with the learning of specific concepts.

\section{LITERATURE REVIEW}

Many studies (e. g. Lauten, Graham, \& Ferrini-Mundy, 1994; Leinhardt, Zaslavsky, \& Stein, 1990; Tall, \& Vinner, 1981) explain that student difficulties in dealing with a function given in graphical form may be a result of traditional instructional methods. Some articles (Orton, 1983; Selden, Selden, \& Mason, 1994) report how even students who performed very well on routine calculus problems found great difficulty and had little or no success in dealing with graphical problems.

Some researchers (Amit, \& Vinner, 1990; Asiala, Cotrill, Dubinsky, \& Schwingendorf, 1997; Dominguez, Barniol, \& Zavala, 2017) discuss specific difficulties that students have with the graphical representation of the derivative. These authors explain some difficulties students have with basic calculus concepts. They explain that some students equate the equation for the line tangent to the graph of a function at a given point with the derivative of the function.

Ferrini-Mundy and Graham (1994) discuss about students' desire to find an equation for a function given only graphically before attempting to plot the graph of the derivative function. Zandieh (2000) described the relation between the derivative and original function as a process of passing through many input values and determining an output value for each of them given by the limit of the difference quotient, and found that only a few of the students she considered included some explanation of covariance. Oehrtman, Carlson, and Thompson (2008) reported that their students were often unable to realize the relation between derivative and original function in the graphical form. Nemirovsky and Rubin (1992) investigated students' understanding about derivative while they worked with graphs, and found that many students sketched a graph for the derivative similar to the original function graph without appreciating the relation between a function and the derivative over the intervals.

In some of the investigations cited (Asiala et al., 1997; Borji \& Voskoglou, 2016, 2017) APOS is used as a theoretical framework. In this approach, many researches use the triad (intra, inter and trans) to investigate students' understanding of different concepts of calculus, in particular the derivative. Badillo et al. (2011) report the level of understanding of the relation between $f^{\prime}(a)$ and $f^{\prime}(x)$ among some calculus teachers. The teachers answered to a questionnaire about their understanding of $f^{\prime}(a)$ and $f^{\prime}(x)$. The authors reported how the comprehension of $f^{\prime}(a)$ and $f^{\prime}(x)$ can be related to the underlying structure of both graphic and algebraic schemes. Clark et al. (1997) used the triad to interpret the stages of understanding of the chain rule schema. Baker et al. (2000) introduced the interaction of two schemas. The authors used the triad to describe student understanding when given a derivative graphing problem. Garcia, Llinares, and Sánchez-Matamoros (2011) reported on different structures of the derivative schema of the students that were considered to be at the trans. They explained that there are different structures in the schema because of the consciousness in which students use the relations between a function and derivative of the function. Fuentealba et al. (2017) used APOS theory and the configuration of the derivative concept to focus on the analysis of students' answers to a sequence of tasks of the derivative. They suggested that thematizing the derivative schema is difficult to achieve and observed delicate differences in responses given by the students who succeeded, indicating differences in the relations between the successive derivatives of a function. 
In the framework of OSA, research has been carried out on the emergence of mathematical objects of differential and integral calculus. In Font and Contreras (2008) it is argued that in order to understand a definition of derivative function, a hypothetical student has to put in operation (plausibly) several semiotic functions. Font $(2000,2005)$ concluded that in the process of calculating $f^{\prime}$ three phases must be considered: (1) Translations between the different forms of representing $f$; (2) the transition from a form of representation of $f$ to a form of representation of $f^{\prime}$; and, (3) translations and conversions between the different forms of representing $f^{\prime}$. In Font (2000) it is analyzed the semiotic complexity of three different ways of introducing the derivative function: (1) Definition by limits; (2) finding a condition that all tangents meet and, from that, calculating said derivative function; and, (3) calculating it by means of the values of the derivative at various points, given in a table.

Currently in the Didactics of Mathematics there is a tendency to find possible relationships between different theories and compare them. In particular, possible connections between the APOS and the OSA are recently on the focus of interest. This is related to an apparent need for APOS development with contributions from semiotic theories (Badillo et al., 2011; Font, Malaspina, Giménez and Wilhelmi, 2011; Font, Montiel, Vidakovic and Wilhelmi, 2011; Trigueros \& Martínez-Planell, 2010) and the fact that in theories (APOS \& OSA) an important cognitive component intervenes.

The starting point to search for connections between the OSA and APOS theory is the inquiry into the use of the notion of "mathematical object" in both theories (Font, Badillo, Trigueros, \& Rubio, 2012; Font et al., 2016). Two relevant aspects to address this issue are: (1) the interest that has had for mathematics education questions about the nature of mathematical objects, their various types, the processes of constitution and forms of participation in mathematical activity and (2) the fact that OSA and APOS are examples of a group of theories that use the term mathematical object as a relevant construct of its theoretical framework. To materialize this dialogue, in Font et al. (2016) a Genetic Decomposition (GD) was developed from APOS for the concept of derivative that was later analyzed from the point of view of OSA, in order to unravel some aspects that are implicit in the mechanisms of APOS related to the emergence of objects, and thus understand better its complexity and the possible relation between mental constructions. Results of this networking showed some commonalities and some links between these theories and signaled the complementary nature of their constructs.

In this article, we analyze students' understanding to solve one graphing problem in relation to the first derivative and characterize their schemas in terms of levels (intra, inter and trans) of development of the schema. As it has been said in the literature review, many studies have explained that it is hard for students to understand the construction of the derivative function in relation to the original function in the graphical representation. With the aim of having a better comprehension of the students's problems, we will use two lens: APOS and OSA that have already been used in other investigations (Badillo et al., 2011; Font, Badillo, Trigueros, \& Rubio, 2012; Font, Malaspina, Giménez, \& Wilhelmi, 2011; Font, Montiel, Vidakovic \& Wilhelmi, 2011; Font et al., 2016; Font, Trigueros, Badillo \& Rubio, 2012; Trigueros \& Martínez-Planell, 2010).

\section{THEORETICAL FRAMEWORK}

In this section, we explain the two theoretical frameworks used (APOS and OSA) and the relationship between them.

\footnotetext{
APOS

The APOS theory characterizes the mathematical knowledge of a student as their tendency to respond to problematic mathematical situations by reflecting on problems and their solutions within a social context and the construction or reconstruction of actions, processes and objects, organizing them into schemas to deal with this situation (Dubinsky, \& McDonald, 2001). APOS is an acronym for these constructs (Action, Process, Object and Schema). A concept is first conceived as an Action, that is, as an externally directed transformation of a previously conceived Object (or Objects). An action is external in the sense that each step of the transformation needs to be performed explicitly and instructed by external guidance; additionally, each step operates the next, that is, the steps of the Action cannot be imagined and none can be skipped. When an action is repeated and the student reflects on it, this action may be interiorized into a Process. At this conception, the student may imagine taking the action and may anticipate its result without having to explicitly do the action. When they need to do transformations on these processes, the student encapsulates them into Objects and now can use actions on these newly constructed entities. A Schema is constructed as a coherent collection of Actions, Processes, Objects, and other Schemas, and connections among these constructs.

Schemas develop as connections between new and previous actions, processes, objects and other schemas. Their development may be explained by three stages that Piaget and García (1983) mentioned as the "triad": Intra, inter and trans. At intra level, the newly constructed object is present, together with other objects and processes, but the individual is not aware of the connections that might exist between them. At inter level, actions and processes
} 
between objects are constructed so that the recognition of relations between processes and objects, and transformations between them are starting to be made. Trans level is identified by being conscious of the complete formation and being able to decide whether a special situation can be resolved by this schema (Arnon et al., 2014).

In APOS, objects emerge as a result of two mechanisms: Encapsulation and Thematization. Encapsulation is a mechanism based on reflective abstraction. It refers to the possibility of thinking of a process as something complete and being able to characterize it and study its properties. Through encapsulation, abstract notions are conceived as objects having properties and various representations. Thematization involves the possibility of thinking the schema (or several) as a whole, to act or make transformations about it and study its properties. It also involves the possibility of dissecting, analyzing, examining its parts and re-composing it as a whole. The encapsulation of processes into objects and especially the thematization of a schema (or several) into an object (as well as its reverse mechanism) are related to complexity of the mathematical objects and the necessary articulation of the elements in which this complexity bursts.

APOS theory includes, as part of its application to research and teaching, a general model describing a possible way to construct the concept or topic of interest. This hypothetical model is called the Genetic Decomposition (GD) which includes a theoretical analysis of the actions, processes, objects, and schemas that a learner may construct in order to learn a certain mathematical concept. It is used to design research and instructional methods. The genetic decomposition of a mathematical topic is not unique and, in a certain way, it is linked to the instructional context for which it is constructed.

\section{OSA}

The OSA is a theory that describes the mathematical activity from an institutional and personal point of view. In this theory, it is important to consider the objects involved in such activity and the semiotic relations between them (Breda, Pino-Fan, \& Font, 2017; Font, Godino, \& Gallardo, 2013; Rondero \& Font, 2015). In OSA the mathematical activity can be modelled in terms of configuration of primary objects and processes that appear during the practice. A mathematical practice is considered in this theory as a sequence of actions, controlled by institutionally accepted rules, oriented towards an objective (usually solving a problem). In this theory the word 'object' is used in a big sense to refer to anything which is susceptible to be considered as an entity which is, in some way, included in mathematical practice and can be recognized as a unit. E. g., when assessing a problem solving practice, we can describe the use of different languages (graphic, symbolic, verbal ...). These languages are the ostensive part of a set of definitions, procedures and propositions that are involved in argumentation and justification of the problem solution. Problems, languages, definitions, procedures, propositions and arguments are used as objects, the six mathematical primary objects. Connected together they form configurations of primary objects. Configuration of objects in OSA can be seen both from a personal (cognitive) and from an institutional (epistemic) view. In the following lines we give more explanations about primary objects.

Language: Terms, expressions, notations, graphs, etc. in their various registers (written, oral, gestural, etc.).

Problems: Extra-mathematical applications, tasks, exercises, examples, etc.

Concepts/definitions: Introduced by means of definitions or descriptions, explicit or otherwise (straight line, point, number, mean, function, etc.).

Propositions: Statements about concepts, etc.

Procedures: Algorithms, operations, techniques of calculation, etc.

Arguments: Statements used to validate or explain the propositions and procedures, whether deductive or of another kind.

\section{Relation between APOS-OSA}

A relation between some of the principal aspects of both theories is explained as follows (Font et al., 2016).

\section{Action versus practice}

The terms of action (in APOS) and practice (in OSA) are complementary. In APOS an action is a transformation of mathematical objects that is made by a student based on some explicit algorithms and is observed by the subject as externally. In the OSA a practice is considered as a series of mathematical actions controlled by rules. The set of these rules forming the practice is categorized into types of primary objects. A difference between action in APOS and practice in OSA is that actions are mental constructions in the mind of an individual while practice in OSA is a collection of actions based on rules in the community. 


\section{Process versus procedure}

In APOS when the individual reflects on the action and constructs an internal operation that performs the same transformation, then we say that the action has been interiorized to a process. In OSA procedures are assumed to be rules about how to use mathematical objects. In OSA a practice is understood as a collection of mathematical actions made by rules that can be considered as different types of primary objects. One of these objects is the procedure, which is a rule of steps to carry out the practice, or a part of the practice. A procedure can also be considered complementary to a process in APOS when an individual shows to have interiorized mental actions and is aware of the result of the process.

\section{Encapsulation versus primary object}

Encapsulation occurs when an individual applies an Action to a Process, that is, sees a dynamic structure (Process) as a static structure to which Actions can be applied. The result of encapsulation of a process is a mental object. From the perspective of OSA, encapsulation makes a double change in nature. On the one hand, from process to object which is a primary object based on OSA. On the other hand, encapsulation produces a change in the nature of the mathematical object associated to the cognitive object, since there is often a change from a procedure to a definition.

\section{Cognitive configuration versus schema}

The terms of cognitive configuration in OSA and schema in APOS can be considered as complementary. A schema is a coherent set of actions, processes, objects, and other schemas that are related in the student's mind. A schema is coherent in the sense that given a problem situation, the student has an explicit or implicit path of deciding if the problem falls within this schema. In OSA the notion of cognitive configuration is a tool for explaining the objects involved and emerging from personal practices, and therefore, to explain the subject's knowledge, understanding and skills in the learning process. A cognitive configuration may reveal the complexity of a particular task linked to a schema. In fact, schema and cognitive configuration are different but complementary. A cognitive configuration is connected to a specific task, whereas a schema is related to types of tasks.

\section{METHODOLOGY}

This research is a multiple case study in which 14 students participated voluntarily. The freshman students were enrolled in Electrical Engineering, Mathematics, and Physics at one of Iran's universities. All of them had completed a Calculus 1 course (single-variable calculus) in the same semester. Their textbook was Stewart Calculus, 2010. All students participated voluntarily in our research, at the end of which they received rewards of appreciation. The time interval between the end of their Calculus course and the interviews was approximately one month.

The methodology consists of the following steps: First, we posed one problem where the graph of a function includes some critical points and asked the students to draw the graph of $f^{\prime}$ function and collected the students' solutions. Second, we analyzed the mathematical activity following the methodology of onto-semiotic analysis (Pino-Fan, Godino, \& Font, 2018), which consists of the analysis of mathematical practices and then considering the mathematical primary objects that were activated during these practices. Third, we made a genetic decomposition based on APOS theory. Our genetic decomposition describes the mental constructions that might be needed when students use the objects described in the second phase to solve these type of problems (this GD has been triangulated by two APOS experts). Fourth, we made the transcripts of the resolution of the task. Fifth, we analyzed the transcripts to determine the practices, the objects, and mental constructions of the GD and we assigned a level of development (intra, inter or trans) of the schema for sketching $f^{\prime}$ when given the graph of $f$.

These steps include an interview with each participating student, in which they were asked about some aspects of their written answers. Therefore, two instruments were used for data collection: an interview and a questionnaire with a complex task. It is consistent with the methodology required by the theoretical framework of APOS.

\section{First step: The Problem}

Task: For the function $f$ whose graph is given,

1. Arrange the following numbers in increasing order and explain your reasoning:

$$
f^{\prime}(a), f^{\prime}(b), f^{\prime}(c), f^{\prime}(d)
$$

2. State, with reasons, where the function $f$ is not differentiable.

3. Sketch the graph of $f^{\prime}$. 


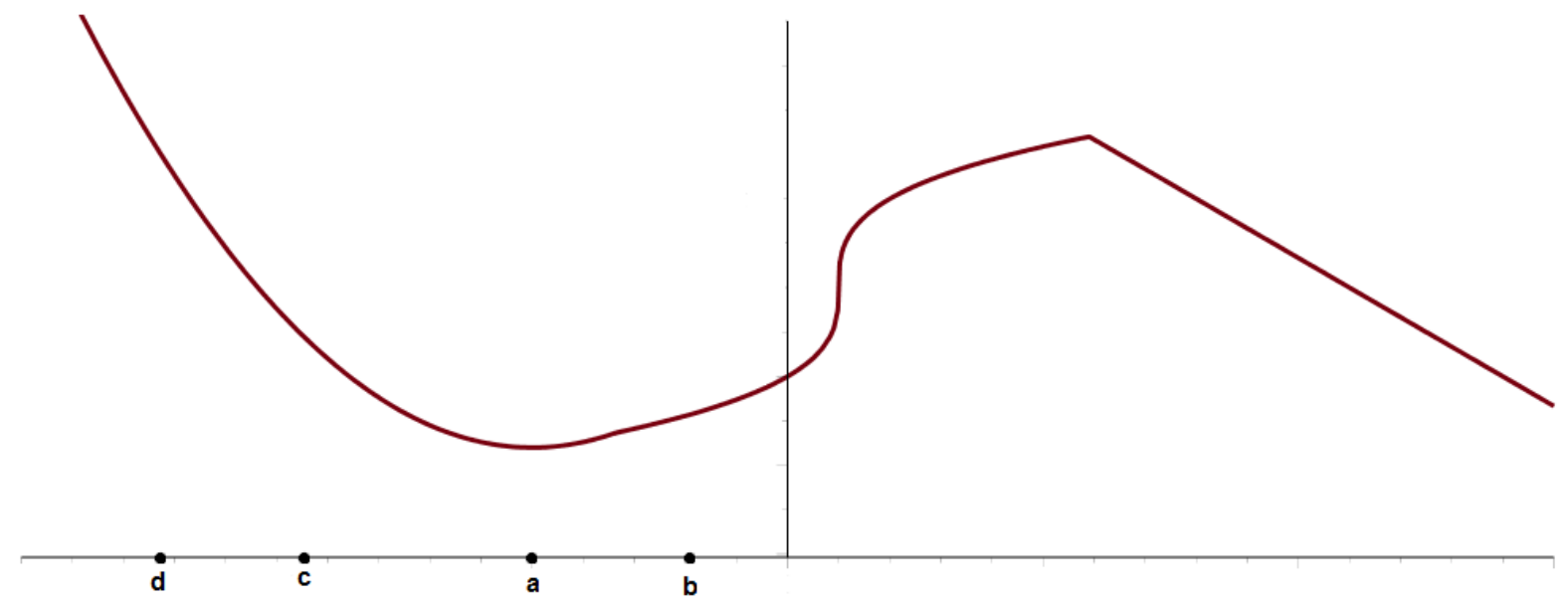

We gave the students a graph of the continuous function $f$ that includes three critical points and asked them to answer the three questions. The main focus of our research was on question 3, sketching the graph of $f^{\prime}$ from the graph of $f$, and we only wrote students' transcriptions of this question in this research. However, whenever it was necessary, we have considered students' responses to questions 1 and 2 . It should be noted that in the context of the course where this problem was proposed, the second question meant finding the points at which $f^{\prime}\left(x_{0}\right)$ does not exist. The data has been collected through worksheets, which contain the problem statement and its resolution (usually a graph). Figure 1 is an example of an answer to question 3.

In what follows, we show more information about the relation between the task and the theoretical framework and the way the data was analyzed and how we arrived to the results. The students answered a graphical question about sketching the graph $f^{\prime}$ when given the graph $f$ and after it, each of them explained their thinking processes. The interviewers were two of the authors of this article. The interviews were recorded as videos. Afterwards, we transcribed the video-files and collected students' sheets. The question designed in this study is complex because it required the student to use actions, processes, objects, and schemas (in the framework of APOS) and also practices and primary objects (in the framework of OSA) in order to sketch the graph of $f^{\prime}$ from seeing the graph of $f$. For this reason, we described the primary objects, based on OSA, and the mental constructions, based on APOS, that a student might make to develop her or his understanding of the question, which allowed us to determine different levels of development of the schema (intra, inter and trans). In our analysis of students' responses, we used these theoretical tools to characterize students' understanding in terms of the development of their schemas (intra, inter and trans).

\section{Second step: A look from the OSA}

We make an a priori analysis of the mathematical activity to solve the problem in terms of practices performed and objects, based on OSA theory.

\section{Practice}

1) Read the task.

2) Write a text with one argumentation for the questions 1 and 2.

3) Sketch a graph of $f^{\prime}$.

\section{Epistemic configuration (EC)}

Problems: The task proposed.

Languages:

Verbal: point, line, tangent line, function, graph of a function, constant function, slope, order, decreasing, increasing, derivative at a point.

Symbolic: $a, b, c, d, f^{\prime}(a), f^{\prime}(b), f^{\prime}(c), f^{\prime}(d), f^{\prime}$

Graphic: The graphic of $f$ and $f^{\prime}$ (solution)

Definitions: 
Point, line, function, graph of a function, constant function, tangent line, slope, order, decreasing, increasing, derivative at a point.

It is important to emphasize that the slope is understood as the variation of the dependent variable per unit of the independent variable, and the derivative at a point as the slope of the tangent line.

\section{Procedures:}

Pr0: Sort real numbers.

Pr1: Determine a point of the graph by knowing its abscissa (Evaluate the function at $\mathrm{x}=$ a graphically).

Pr2: Sketch the tangent line at a point.

Pr3: Determine the value of the sign of the slope.

Pr4 Procedure for sketching a graph of $f^{\prime}$ from $f$ :

Pr4a) Determine several points on the graph of $f$ and sketch the tangent lines and visually compare the slope of tangent lines to determine the order relation between them.

Pr4b) Determine the intervals where $f^{\prime}$ is increasing and decreasing.

Pr4c) Determine several points on the graph of $f$ and sketch the tangent lines and visually compare the slope of tangent lines to determine the speed of the variation of the inclination of the tangent lines.

Pr4d) Determine the intervals of upward and downward concavity of $f^{\prime}$.

Pr4e) Determine graphically the intervals where the function $f^{\prime}$ is increasing, decreasing, concave upward, concave downward and critical points and make the sketch of the graph of $f^{\prime}$ using information from the previous procedures.

\section{Propositions:}

1) When the line is parallel to the $x$-axis, the slope is equal to zero.

2) If a function is increasing at $x=a, f^{\prime}(a)>0$ and the slope of the tangent line is positive.

3) If a function is decreasing at $x=a, f^{\prime}(a)<0$ and the slope of the tangent line is negative.

4) When the line is parallel to the $y$-axis, slope does not exist (because the value is infinity).

5) The cut-off points of the graph with the abscissa axis are those in which the second ordinate is zero.

6) If the tangent at a point is parallel to the $x$-axis, then the derivative is 0 there and the graph of $f^{\prime}$ crosses the $x$-axis at that point.

7) If in an interval the graph of $f$ is increasing/decreasing, the graph of $f^{\prime}$ is positive/negative in that interval.

8) If in an interval the graph $f$ is concave upward/downward the graph of $f^{\prime}$ is increasing/decreasing on that interval.

9) If in an interval, the variation on the values of the slope of the tangent line to a function is constant, then $f^{\prime}$ is a line. If in an interval, the slope of the tangent line decreases and the variation on the values of the slope increases/decreases, then $f^{\prime}$ is concave downward/upward. If in an interval, the slope of the tangent line increases and the variation on the values of the slope increases/decreases, then $f^{\prime}$ is concave upward/downward.

10) If the tangent at a point is parallel to the $y$-axis, there is no slope (because it cannot be divided by zero).

11) If the graph of $f$ contains a cusp, then the left and right tangents differ and $f^{\prime}$ does not exist at that point.

Arguments:

Answer to the question 1)

$f^{\prime}(b)$ is greater than zero because the tangent line is increasing and its slope is positive .

$f^{\prime}(a)$ is zero because the tangent line is parallel to the $x$-axis.

$f^{\prime}(d)$ and $f^{\prime}(c)$ are negative because the tangent lines in these points $(x=d, c)$ are decreasing.

While $f^{\prime}(d)$ has greater slope than $f^{\prime}(c)$ in absolute value, since both are negative, $f^{\prime}(d)<f^{\prime}(c)$. At the same time, $f^{\prime}(d)$ and $f^{\prime}(c)$ are smaller than $f^{\prime}(a)$ because the latter is zero. Finally $f^{\prime}(b)$ is positive and greater than the previous ones. So, $f^{\prime}(d)<f^{\prime}(c)<f^{\prime}(a)<f^{\prime}(b)$.

Answer to the question 2)

There is a point on the graph of the function $f$ in which the tangent line is parallel to the axis of ordinates, and in this case there is not slope.

There is a point where the graph has a pointed shape, in this case there is no tangent line and therefore there is not derivative at this point. 
Answer to the question 3)

The function $f^{\prime}$ assigns to each value of the independent variable the derivative of $f$ in this value. The derivative is the slope of the tangent line. Graphically, we can visually estimate the slope of the tangent line, which allows us to see that in the interval between $d$ and $a, f^{\prime}$ is increasing. In $x=d$ the tangent line has a greater slope in absolute value than in the points of the abscissa greater than $d$ and less than $a$. Therefore, as the slopes are negative, we see that these are increasing as we approach $x=a$. At this point the graph intersects the abscissa axis since $f^{\prime}(a)=0$.

In $x=b$ the tangent line has a greater slope (in absolute value) than in the points of the abscissa lower than $b$ and the same happens with any other value between $b$ and the abscissa in which the graph of $f$ is parallel to the axis of ordinates and, therefore, being the slopes positive, graph of $f^{\prime}$ grows towards infinity.

At the point where the tangent line is parallel to the axis of ordinates there is no slope, then for the values greater than the abscissa at this point the tangent line is increasing, with positive slope, but the slope has a smaller increase than in the points with lower abscissa. Therefore, since the slopes are positive, we see that these are diminishing as we approach the point where the graph has a pointed (corner) shape. At this point there is not derivative, there is a discontinuity in the graph of $f^{\prime}$. In the points with abscissa greater than the corner point, the graph is a straight line so the tangent line coincides with it. Then, for all values of abscissa greater than that of the pointed (corner) point, the slope is always the same and the graph is constant.

\section{Third step: A look from the APOS (Genetic Decomposition)}

In order to carry out the practices described in the previous section (in particular for sketching the graph of $f^{\prime}$ ) according to the OSA, it is necessary for the student to perform the following actions from the point of view of APOS. In the following lines, we describe mental constructions that a student might need to construct in order to learn or solve this type of problems, sketching the graph of $f^{\prime}$ when given the graph of $f$.

Action 1: Determine the points where the derivative exists. For those points where it exists, estimate graphically the value of sign of the derivative at the point $A(a, f(a))$.

Action 2: Sketch approximately the point $A^{\prime}\left(a, f^{\prime}(a)\right)$.

Action 3: Compare and order the slopes of the tangents in two or more points of the graph of the function.

Process 1: Interiorization and mental repetition of above actions for finding and draw intervals of increment and decrement of $f^{\prime}(x)$.

Object 1: Encapsulation the process 1 to an object conception (Relation between the graph $f$ and increasing/decreasing of the graph $f^{\prime}$ on the corresponding interval).

Process 2: Interiorization and mental repetition of above actions for finding and draw intervals of upward and downward concavity of the graph $f^{\prime}(x)$.

Object 2: Encapsulation the process 2 to an object conception (Relation between the graph $f$ and upward/downward concavity of the graph $f^{\prime}$ on the corresponding interval).

Process 3: Coordination of the two processes above described into a new process in which the sketch of the graph of $f^{\prime}$ can be obtained from the graph of $f$.

Schema: Establishing relations between these actions, processes and objects with others (slope, line, tangent line, estimations of real numbers, function, derivative, derivative at one point, graph, angle, etc.) to construct a schema for the sketch of the graph of $f^{\prime}$ from a graph of $f$.

These mental constructions allow the student to make the graph of $f^{\prime}$ from the graph of $f$ so that the student is able to sketch the graph $f^{\prime}(x)$ as a standard and canonical graph throughout the whole domain.

\section{Relation between EC, GD and Levels of Development of the Schema}

In the APOS, the GD is a model of the predicted constructions that students should make in the process of learning a concept, it does not allow the students to perform anything, since it is a theoretical model it cannot allow anything to students. From the point of view of OSA, the EC is activated when the students perform practices. So then, from the perspective of OSA, the mental constructions of the GD allow the student to perform the practice that solves the problem and activate the EC described in section "Second step: A look from the OSA". The actions described in this GD in terms of the OSA would be part of the practice that the student makes to solve the problem. These practices are regulated by the primary objects of the EC, especially by the procedures, in some way are equivalent to the processes of the GD (process 1 of GD is similar to procedures Pr4a and Pr4b and process 2 is similar to procedures Pr4c, Pr4d and pr4e; process 3 is similar to the whole Pr4 procedure). The objects of this GD are similar to some propositions of the EC, Object 1 is similar to the proposition 8 , and object 2 is similar to proposition 9. The schema is similar to all EC. 
In Table 1, we present some relations between mental construction described in the GD and primary objects described in the EC. At the same time, the GD is described in terms of the characteristics of the levels of development of the Schema.

Table 1. Some relations between GD, EC and levels of development of the schema

\begin{tabular}{|c|c|c|}
\hline EC (OSA) & GD (APOS) & Levels of development of the Schema (APOS) \\
\hline $\begin{array}{l}\text { Procedures: } \operatorname{Pr} 0, \operatorname{Pr} 1, \operatorname{Pr} 2 \text { and } \operatorname{Pr} 3 \\
\text { Propositions: } 1,2,3,5 \text { and } 6 \\
\text { Arguments: The student cannot respond to the } \\
\text { questions } 1,2 \text { and } 3 \text { of the task. It is } \\
\text { remarkable that this student cannot make the } \\
\text { procedure } 4 \text { and for this reason he cannot } \\
\text { sketch well the graph of } f^{\prime} \text {. }\end{array}$ & $\begin{array}{l}\text { Action 1: Determine the points where } \\
\text { the derivative exists. For those points } \\
\text { where it exists, estimate graphically the } \\
\text { value of sign of the derivative at the } \\
\text { point } A(a, f(a)) \text {. } \\
\text { Action 2: Sketch approximately the } \\
\text { point } A^{\prime}\left(a, f^{\prime}(a)\right) \text {. } \\
\text { Action } 3: \text { Compare and order the slopes } \\
\text { of the tangents in two or more points } \\
\text { of the graph of the function. }\end{array}$ & $\begin{array}{l}\text { Intra level: The student uses only the positive/negative } \\
\text { value of } f^{\prime} \text { and does not have any notice on } \\
\text { increasing/decreasing } f^{\prime} \text { on different intervals and does } \\
\text { not identify the points where the derivative does not } \\
\text { exist. The student can perform some mental } \\
\text { constructions of the GD considered as actions, but there } \\
\text { are some mistakes because some of the propositions of } \\
\text { the EC are not considered and fails applying some } \\
\text { procedures. The student cannot sketch well the graph of } \\
f^{\prime} \text { because he/she has not constructed the necessary } \\
\text { relations between actions, processes, objects and other } \\
\text { schemas. }\end{array}$ \\
\hline
\end{tabular}

Procedures Pr4a and Pr4b: Determine several

points on the graph of $f$ and sketch the

tangent lines and visually compare the slope of

tangent lines to determine the order relation

between them. Determine the intervals where

$f^{\prime}$ is increasing and decreasing.

Propositions: 7 and 8

Arguments: The student can respond to the

question 1 of the task. In relation to the

question 2, the student can only find the

corner point as a point that is not

differentiable. Concerning question 3 , the

student can sketch correctly the graph $f^{\prime}$ only

in some parts of the domain.

The fact that he/she does not know

propositions 9, 10 and 11, impedes correct

drawing of the graph of $f^{\prime}$.

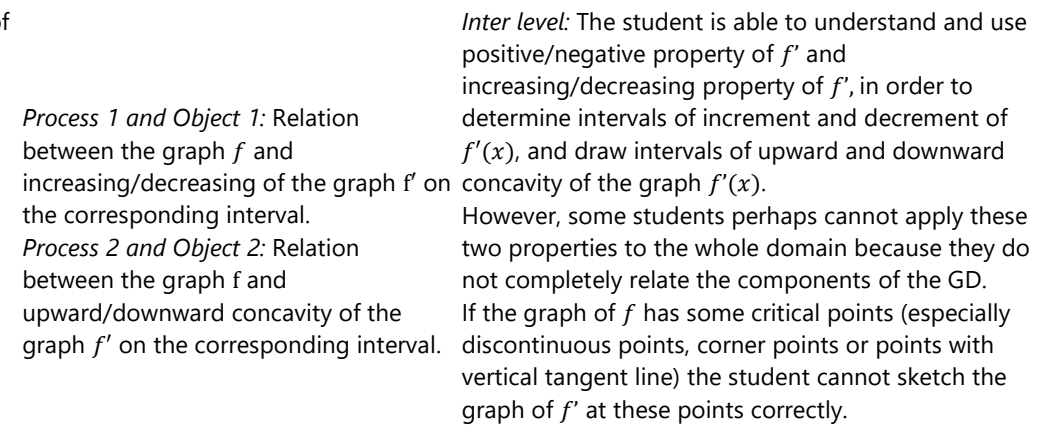

Process 3: Coordination of the two processes above described into a new process in which the sketch of the graph of $f^{\prime}$ can be obtained from the graph of $f$.

Schema: Actions, Processes, Objects, and other Schemas, and connections among these constructs.
Trans level: The student is able to sketch the graph $f^{\prime}$ based on both the sign property of $f^{\prime}$ (positive/negative) and the monotonic property of $f^{\prime}$ (increasing/decreasing) throughout the domain The student is able to consider the critical points of $f$ and sketch the graph $f^{\prime}$ at these points correctly.

\title{
Fourth Step: Example of Transcription with the Description of Actions and Gestures of the Student
}

\begin{abstract}
Farzaneh: At $x=a$, derivative is zero because tangent is parallel to the $x$-axis and I plot $(a, 0)$ on the $x$-axis. From $-\infty$ to a graph $f$ is decreasing then I sketch graph $f^{\prime}$ below $x$-axis and connect it to $(a, 0)$. From a to vertical tangent place, graph $f$ is increasing therefore $f^{\prime}$ on this interval is positive and its graph is above $x$-axis. At vertical tangent place, $f^{\prime}$ tends to $\infty$. From vertical tangent place to corner point, graph $f$ is increasing and values of slopes on this interval are decreasing (she sketches her graph on this interval). For the corner point, I plot a hollow point on the $x$-axis (she has difficulties in her sketching after the corner point). (Figure 2).
\end{abstract}

\section{RESULTS}

We analyzed the mathematical activity in the students' responses and characterized their schemas into three groups (Table 2), which can be associated with intra, inter and trans levels of development of a schema, as described in Table 1. In our analysis, there were ten students who had constructed their schemas at the intra level, three students who had constructed their schemas at the inter level, and only one student who had constructed a schema at the trans level. Due to the limitations of the space on the paper, we present only one example of the analysis of 
student's responses that allows to characterize their schemas in each level of the triad. To relate OSA and APOS, we also analyzed the responses of students in each level based on EC of the OSA.

Table 2. Levels of development of students' schemas

\begin{tabular}{cccc}
\hline Level of triad & Intra & Inter & Trans \\
\hline Number of students & 10 & 3 & 1 \\
\hline
\end{tabular}

\section{First Group: Intra Level}

Behnaz was one of the students who constructed a schema at the intra level. We present the transcription of her answer.

Behnaz: The derivative at $x=a$ is zero (she plots the point $(a, 0)$ on the $x$-axis). Before a, graph $f$ is decreasing therefore graph $f^{\prime}$ is the below $x$-axis. In $a$, derivative is zero, from a to $b$ the graph $f^{\prime}$ is above $x$-axis (she sketches her graph in interval $[a, b]$ ). From $b$ to the corner point, the graph of $f$ is increasing. At the corner point, there is not derivative (but she cannot sketch it correctly). After corner point, the graph $f$ is decreasing therefore graph $f^{\prime}$ is below $x$-axis (Figure 1).

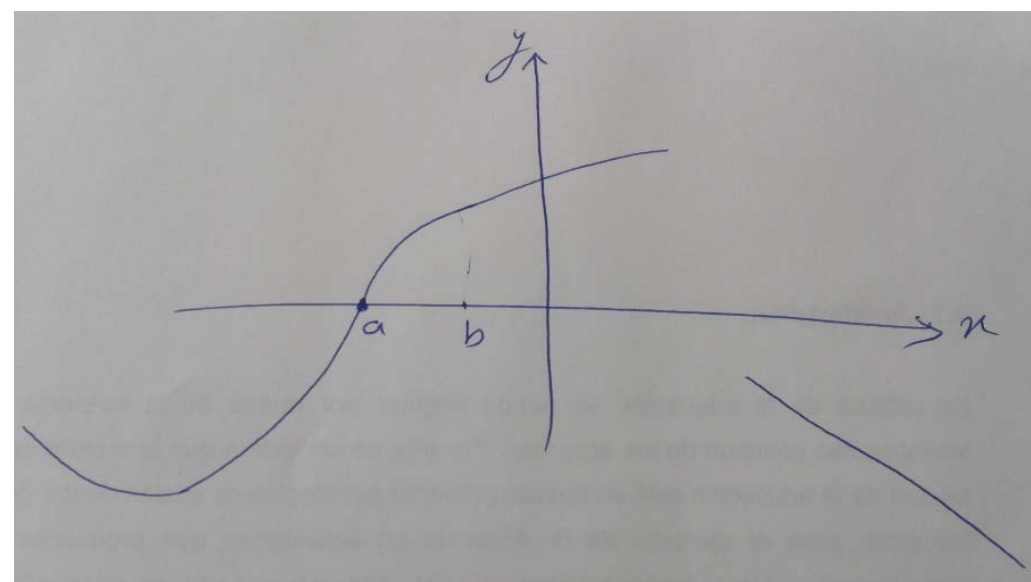

Figure 1. Behnaz's graph (Intra level)

Behnaz is able to understand some properties of the graph of $f^{\prime}$, she uses only the positive/negative value of $f^{\prime}$ and does not have any notice on increasing/decreasing $f^{\prime}$ on different intervals and does not identify the points where the derivative does not exist. Behnaz can perform some mental constructions of the GD considered as actions.

Behnaz can do only the procedures: Pr0, Pr1, Pr2 and Pr3, propositions: 1, 2, 3, 5 and 6 of EC. With respect to arguments in EC, she cannot respond to the questions 1, 2 and 3 of the task. It should be noted that this student cannot make the procedure 4 and for this reason she cannot sketch well the graph of $f^{\prime}$.

\section{Second Group: Inter Level}

Farzaneh was one of the students who constructed a schema at the inter level. Her graph is in the Figure 2.

Farzaneh: At $x=a$, derivative is zero because tangent is parallel to the $x$-axis and I plot $(a, 0)$ on the $x$-axis. From $-\infty$ to a graph $f$ is decreasing then I sketch graph $f^{\prime}$ below $x$-axis and connect it to $(a, 0)$. From a to vertical tangent place, graph $f$ is increasing therefore $f^{\prime}$ on this interval is positive and its graph is above $x$-axis. At vertical tangent place, $f^{\prime}$ tends to $+\infty$. From vertical tangent place to corner point, graph $f$ is increasing and values of slopes on this interval are decreasing (she sketches her graph on this interval). For the corner point, I plot a hollow point on the $x$-axis (she has difficulties in her sketching after the corner point). 


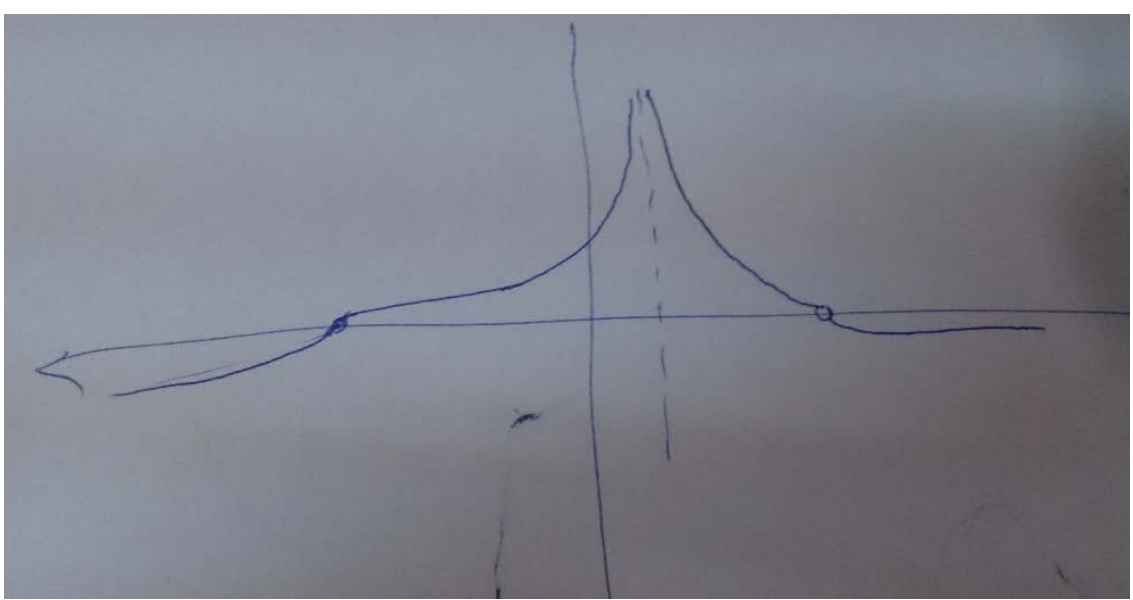

Figure 2. Farzaneh's answer to question 3

Farzaneh is able to understand and use the positive/negative property of $f^{\prime}$ and the increasing/decreasing property of $f^{\prime}$, but she cannot apply these two properties to the whole domain. As the graph of $f$ has some critical points (discontinuous points, corner points or points with vertical tangent line) this student cannot sketch the graph of $f^{\prime}$ at some of these points correctly. In relation to the EC in OSA, she understands and can do only procedures: Pr0, Pr1, Pr2, Pr3, Pr4a and Pr4b and also uses propositions: 1, 2, 3, 5, 6, 7 and 8 of EC (in some intervals). The fact that she does not know propositions 9, 10 and 11 impedes correct drawing of the graph of $f^{\prime}$.

With respect to arguments in EC, this student can correctly and completely respond to the question 1 of the task. In relation to the arguments needed to solve the question 2, Farzaneh can find the corner point as a point that is not differentiable, but she cannot draw the graph of $f^{\prime}$ correctly around this point in question 3 of the task. She answers correctly for the point with vertical tangent. Concerning question 3 , she can sketch correctly the graph $f^{\prime}$ only in some parts of the domain.

\section{Third Group: Trans Level}

Sanaz was the only student who constructed a schema at the trans level (Figure 3).

Sanaz: I know that at $x=a$, derivative is zero so graph $f^{\prime}$ crosses $x$-axis in $(a, 0)$. From $-\infty$ to a, slopes are increasing and their values tend to zero, $f^{\prime}$ is negative (then she sketches the graph of $f^{\prime}$ on this interval). From a to vertical tangent place the slopes are increasing and in vertical tangent place, slope value tends to $+\infty$ (then she sketches the graph of $f^{\prime}$ on this interval). Between vertical tangent place and the corner point, the graph off is increasing therefore $f^{\prime}$ is positive but in this interval slopes' values change from $+\infty$ to positive number, therefore $f^{\prime}$ is decreasing and has concavity upward (then she sketches the graph of $f^{\prime}$ on this interval, decreasing with an upward concavity). In corner point, there are different values for the slope of the tangent line at each side of it. Therefore, the graph of $f^{\prime}$ is

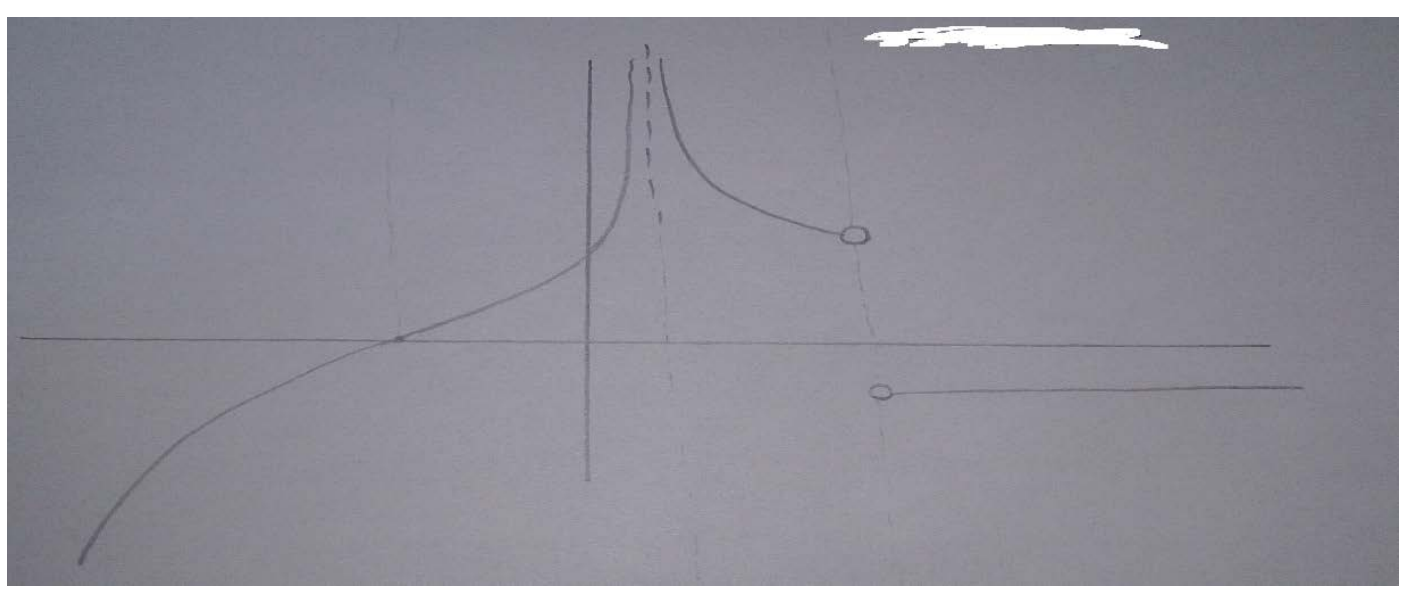

Figure 3. Sanaz's graph (trans level) 
discontinuous (then she plots a hollow point). After corner point the graph of $f$ is a line, therefore its derivative is a constant negative number because the graph of $f$ is decreasing on this interval.

Sanaz is able to sketch the graph $f^{\prime}$ based on both the sign property of $f^{\prime}$ (positive/negative) and the monotonic property of $f^{\prime}$ (increasing/decreasing) throughout the domain. She is able to consider the critical points of $f$ and sketch the graph of $f^{\prime}$ at these points correctly. In relation to the EC of the OSA, this student can correctly draw the graph of the function $f^{\prime}$ from the graph of $f$ because she can activate all the primary objects of the EC and can use them correctly in problem solving process.

\section{CONCLUSION}

We want to emphasize that we used the APOS theory to determine which mental constructions (actions, processes, objects and schemas) are involved in the resolution of the task. We used OSA to identify primary objects (problems, languages, concepts/definitions, procedures, propositions and arguments) that are present when previous mental constructions are made. On the other hand, we related the existence or lack of mental constructions and primary objects to the difficulties identified in students' responses, which enables us to characterize students' schemas in levels intra, inter or trans.

The results show that most of the students in our study had major problems in developing mental constructions and performing the practical work needed to solve the problem, particularly those mental constructions that have to be made to calculate the derivative at the critical points and to determine the speed of the variation of the inclination of the tangent lines to $f$, which is why most of them (10 students) have constructed a schema at the intra level of development of the schema for sketching $f^{\prime}$ when given the graph $f$.

Since all students in our research (except one of them) have constructed their schemas at the intra (10 students) and inter level (3 students), here we give more details about their problems of understanding, especially at the critical points.

Considering the whole domain of the function, on intervals where $f$ is increasing/decreasing, $f^{\prime}$ is positive/negative and on intervals where $f$ is concave upward/downward, $f^{\prime}$ is increasing/decreasing. Some students sketched a graph for $f^{\prime}$ similar to the graph $f$ without appreciating the relation between a function and the derivative over the intervals. They did not mention in their explanations, that if $f$ is increasing then $f^{\prime}$ will be positive and if $f$ is decreasing then $f^{\prime}$ will be negative. This phenomena is also reported in Nemirovsky and Rubin (1992). The second group of student had a higher level of understanding than the first group; they explained that if $f$ is increasing, then $f^{\prime}$ would be positive and situated above the $x$-axis and vice versa. However, they did not notice the relation between the concavity of $f$ and increasing/decreasing value of $f^{\prime}$.

The graph of the function $f$ includes three critical points, one at $x=a$ where derivative is zero, another one at the vertical tangent where the slope does not exist, and the last one at the corner point. All our students (except one of them) had good understanding of the first critical point. At $x=a$, they knew the graph of $f^{\prime}$ must pass through $(a, 0)$. However, most of the students had difficulties at the vertical tangent and the corner point. A significant number of students had problems for sketching $f^{\prime}$ in the interval between the point with the vertical tangent and the corner point and also in the interval between corner point and $+\infty$ (the interval where $f$ is a descending line).

We obtain many results about students' problems on the vertical tangent. Some of the students did not know that the slope of a vertical line does not exist (for instance, when we asked them what is the slope of the line $x=1$, some of them answered that the slope of this line is equal to 1) and they simply ignored the vertical tangent and counted it as a differentiable point of $f$. Some of the students knew that the slope of a vertical line does not exist, but they could not sketch the graph of $f^{\prime}$ at this point because their graph did not lead to $+\infty$. One group of them presented this point as a hole point on the graph $f^{\prime}$. In other group, their graph went to infinity at the left side of the vertical tangent, though they encountered problems plotting $f^{\prime}$ at the right side of the vertical tangent and did not know where they had to begin plotting.

We also found interesting results concerning the corner point. For example, when we asked students to draw a tangent on a corner point, some answered that there are infinite number of tangents at the corner point, some others said there is no tangent at the corner point. Most of the students did not know that there are only two tangents at the corner point, right and left derivatives are not equal. The graph of $f^{\prime}$ of most of students in this point was continuous. Also, we found that students usually encountered two general problems in the case of corner point. The first group explained that the function had no derivative at this point, but totally ignored this statement, and they sketched one graph for the function $f^{\prime}$ that was continuous and differentiable at that point. The second group showed this point with a hole point on the graph. The graph of $f^{\prime}$ of this group had a removable discontinuity, meaning $f^{\prime}$ was not defined at this point but $f^{\prime}+=f^{\prime}-$.

In the interval between the point with the vertical tangent and the corner point, function $f$ is increasing; therefore, $f^{\prime}$ at this interval is positive, and the graph $f^{\prime}$ must be above the $x$-axis. Moreover, when we considered 
this interval, the slope decreases at each point (the concavity is downward). To put it in other words, derivative leads from positive infinity towards a certain positive number (the left derivative at the corner point); therefore, the graph of $f^{\prime}$ is decreasing at this interval and is above the $x$-axis. Examining students' answers on this interval, we noticed that most of the students had problems to correlate the concavity of the function with the increase or decrease of $f^{\prime}$.

After the corner point, the graph of $f$ is a straight decreasing line, so the slope is constant and negative. Therefore, the graph of $f^{\prime}$ at this interval is a straight line below $x$-axis and parallel to it. On students' answers, we found in general three problems that they normally encountered. The first problem was that some students sketched a straight decreasing line above $x$-axis for this interval. The second group of students sketched the same line similar to the one of the first group but below $x$-axis. The last group sketched a straight line parallel to $x$-axis and above it for this interval, and they did not notice that derivative at this interval is negative. One of the students plotted a decreasing line with a downward concavity below the $x$-axis, for this interval. This particular student stated in her explanation that, since $f$ is decreasing at this interval, $f^{\prime}$ is positioned below the $x$-axis. What this student had not noticed was that the slope on this interval is constant. The difficulties observed with the vertical tangent and corner points are consistent with previous studies, for example Baker et al. (2000).

The future perspectives of this study is to deepen the networking between APOS and OSA and apply it to other Calculus's objects that have been little studied so far. In particular, we are conducting research about students' understanding of implicit differentiation using both frameworks.

\section{REFERENCES}

Amit, M., \& Vinner, S. (1990). Some misconceptions in calculus: Anecdotes or the tip of the iceberg? In G. Booker, P. Cobb, \& T. N. de Mendicuti (Eds.), Proceedings of the 14th International Conference for the Psychology of Mathematics Education, (Vol. 1, pp. 3-10.) Cinvestav, Mexico: PME.

Arnon, I. Cottrill, J., Dubinsky, E., Oktac, A., Roa, S., Trigueros, M., \& Weller, K. (2014). APOS Theory: A Framework for Research and Curriculum Development in Mathematics Education. New York, Heidelberg, Dordrecht, London: Springer.

Asiala, M., Cottrill, J., Dubinsky, E., \& Schwingendorf, K. E. (1997). The development of students' graphical understanding of the derivative. Journal of Mathematical Behavior, 16(4), 399-430. https:/ / doi.org/10.1016/S0732-3123(97)90015-8

Badillo, E., Azcárate, C., \& Font, V. (2011). Analysis of Mathematics teachers' level of understanding of the objects $f^{\prime}(a)$ and $f^{\prime}(x)$. Enseñanza de las ciencias, 29(2), 191-206. https:// doi.org/10.5565/rev/ec/v29n2.546

Baker, B., Cooley, L., \& Trigueros, M. (2000). A calculus graphing schema. Journal for Research in Mathematics Education, 31(5), 557-578. https:/ / doi.org/10.2307/749887

Borji, V., \& Alamolhodaei, H. (2016a, August 28-31). Freshman students' graphical understanding of the first and second derivative based on APOS theory and Schema development. Paper presented in the 47th Annual Iranian Mathematics Conference: Kharazmi University, Tehran, Iran.

Borji, V., \& Alamolhodaei, H. (2016b, September 6-8). Students' understanding of the derivative concept based on APOS framework. Paper presented in the 14th Iranian Mathematics Education Conference (IMEC14), Shiraz, Iran.

Borji, V., \& Voskoglou, M. G. (2016). Applying the APOS Theory to Study the Student Understanding of the Polar Coordinates. American Journal of Educational Research, 4(16), 1149-1156. https:/ / doi.org/10.12691/education4-16-5

Borji, V., \& Voskoglou, M. G. (2017). Designing an ACE Approach for Teaching the Polar Coordinates. American Journal of Educational Research, 5(3), 303-309. https:/ / doi.org/10.12691/education-5-3-11

Breda, A., Pino-Fan, L., \& Font, V. (2017). Meta didactic-mathematical knowledge of teachers: criteria for the reflection and assessment on teaching practice. EURASIA Journal of Mathematics, Science $\mathcal{E}$ Technology Education, 13(6), 1893-1918. https:/ / doi.org/10.12973/eurasia.2017.01207a

Clark, J. M., Cordero, F., Cottrill, J., Czarnocha, B., DeVries, D. J., St. John, D., Tolias, G., \& Vidakovic, D. (1997). Constructing a schema: The case of the chain rule? Journal of Mathematical Behavior, 16(4), 345-364. https:/ / doi.org/10.1016/S0732-3123(97)90012-2

Dominguez, A., Barniol, P., \& Zavala, G. (2017). Test of Understanding Graphs in Calculus: Test of Students' Interpretation of Calculus Graphs. EURASIA Journal of Mathematics, Science and Technology Education. 13(10), 6507-6531. https://doi.org/10.12973/ejmste/78085

Drijvers, P., Godino, J. D., Font, V., \& Trouche, L. (2013). One episode, two lenses: A reflective analysis of student learning with computer algebra from instrumental and onto-semiotic perspectives. Educational Studies in Mathematics, 82(1), 23-49. https:/ / doi.org/10.2307/23434838 
Dubinsky, E., \& McDonald, M. (2001). APOS: A constructivist theory of learning in undergraduate mathematics education research. In D. Holton (Ed.), The teaching and learning of mathematics at university level: An ICMI study (pp. 273-280). Dordrecht, The Netherlands: Kluwer.

Ferrini-Mundy, J., \& Graham, K. (1994). Research in calculus learning: Understanding limits, derivatives, and integrals. In J. Kaput \& E. Dubinsky (Eds.), Research issues in Undergraduate mathematics learning (pp. 19-26). Washington, DC: Mathematical Association of America.

Font, V. (2000). Procediments per obtenir expressions simbòliques a partir de gràfiques. Aplicacions a les derivades (Unpublished PhD thesis), University of Barcelona, Spain.

Font, V. (2005). Una aproximación ontosemiótica a la didáctica del análisis. In A. Maz, B. Gómez, \& M. Torralba (Eds.), Investigación en Educación Matemática. Noveno Simposio de la Sociedad Española de la Investigación en Educación matemática (SEIEM) (pp. 109-128). University of Cordoba, Spain.

Font, V., \& Contreras, A. (2008). The problem of the particular and its relation to the general in mathematics education. Educational Studies in Mathematics, 69(1), 33-52. https:/ / doi.org/10.1007/s10649-008-9123-7

Font, V., Badillo, E., Trigueros, M., \& Rubio, N. (2012). La encapsulación de procesos en objetos analizada desde la perspectiva del enfoque onto-semiótico. In A. Estepa et al. (Eds.), Actas del XVI Simposio de la Sociedad Española de Investigación en Educacion Matemática (pp. 239-247). Jaen, Spain: SEIEM.

Font, V., Godino, J. D., \& Gallardo, J. (2013). The emergence of objects from mathematical practices. Educational Studies in Mathematics, 82(1), 97-124. https:/ / doi.org/10.1007/s10649-012-9411-0

Font, V., Malaspina, U., Gimenez, J., \& Wilhelmi, M. (2011). Mathematical objects through the lens of three different theoretical perspectives. In T. Rowland et al. (Eds.), Proceedings of the VII congress of the European society for research in mathematics education (pp. 2411-2420). Rzeszow, Poland: University of Rzeszow.

Font, V., Montiel, M., Vidakovic, D., \& Wilhelmi, M. R. (2011). Analysis of dimensional analogy by means of different theoretical perspectives. In Roberta V. Nata (Ed.), Progress in education, volume 19 (pp. 39-76). Hauppauge, NY: Nova publishers.

Font, V., Trigueros, M., Badillo, E., \& Rubio, N. (2012). What is a Mathematical object? Looking to objects from two theoretical perspectives: APOS and OSA. Pre-Proceedings of the 12th International Congress on Mathematical Education, Seoul, Korea: ICME.

Font, V., Trigueros, M., Badillo, E., \& Rubio, N. (2016). Mathematical objects through the lens of two different theoretical perspectives: APOS and OSA. Educational Studies in Mathematics, 91(1), 107-122. https:/ / doi.org/10.1007/s10649-015-9639-6

Fuentealba, C., Sánchez-Matamoros, G., Badillo, E., \& Trigueros, M. (2017). Thematization of derivative schema in university students: Nuances in constructing relations between a function's successive derivatives. International journal of mathematical education in science and technology, 48(3), 374-392. https://doi.org/10.1080/0020739X.2016.1248508

García, M., Llinares, S., \& Sánchez-Matamoros, G. (2011). Characterizing thematized derivative schema by the underlying emergent structures. International Journal of Science and Mathematics Education, 9(5), 1023-1045. https://doi.org/10.1007/s10763-010-9227-2

Lauten, A., Graham, K., \& Ferrini-Mundy, J. (1994). Student understanding of basic calculus concepts: Interaction with the graphics calculator. Journal of Mathematical Behavior, 13(2), 225-237. https:/ / doi.org/10.1016/07323123(94)90026-4

Leinhardt, G., Zaslavsky, O., \& Stein, M.K., (1990). Functions, Graphs, and Graphing: Tasks, Learning, and Teaching. Review of Educational Research, 60(1), 1-64. https:/ / doi.org/10.3102/00346543060001001

Mackie, D., \& Court, S. (2002). Using Computer Algebra to Encourage a Deep Learning Approach to Calculus. In Proceedings of the 2nd International Conference on the Teaching of Mathematics. Retrieved from http://users.math.uoc.gr/ ictm2/

Nemirovsky, R., \& Rubin, A. (1992). Students' tendency to assume resemblances between a function and its derivatives. TERC Working 2-92. Cambridge MA: TERC.

Oehrtman M. C., Carlson, M. P., \& Thompson P. W. (2008). Foundational reasoning ability that promote coherence in students' function understanding. In M. P. Carlson \& C. Rasmussen (Eds). Making the connection: research and practice in undergraduate mathematics, (pp. 150-171). Washington, DC: Mathematical Association of America.

Orton, A. (1983). Students' understanding of differentiation. Educational Studies in Mathematics, 14(3), 235-250. https://doi.org/10.1007/BF00410540 
Özmantar, M. F., Akkoç, H., Bingölbali, E., Demir, S., \& Ergene, B. (2010). Pre-Service Mathematics Teachers' Use of Multiple Representations in Technology-Rich Environments. EURASIA Journal of Mathematics, Science and Technology Education, 6(1), 19-36. https://doi.org/10.12973/ ejmste/75224

Park, J. (2015). Is the derivative a function? If so, how do we teach it? Educational Studies in Mathematics, 89(2), 233250. https:// doi.org/10.1007/s10649-015-9601-7

Piaget, J., \& García, R. (1983). Psychogenesis and the history of science. New York: Columbia University Press.

Pino-Fan, L., Font, V., Gordillo, W., Larios, V. \& Breda (2017). Analysis of the Meanings of the Antiderivative Used by Students of the First Engineering Courses. International Journal of Science and Mathematics Education, 1-23. (online) https:/ / doi.org/10.1007/s10763-017-9826-2

Pino-Fan, L., Godino, J. D., \& Font, V. (2011). Faceta epistémica del conocimiento didáctico-matemático sobre la derivada. Educação Matemática Pesquisa, 13(1), 141-178.

Pino-Fan, L., Godino, J. D., \& Font, V. (2018). Assessing key epistemic features of didactic-mathematical knowledge of prospective teachers: the case of the derivative. Journal of Mathematics Teacher Education. 21(1), 63-94. https:/ / doi.org/10.1007/s10857-016-9349-8

Robles, M. G., Telechea, E., \& Font, V. (2014). Una propuesta de acercamiento alternativo al teorema fundamental del cálculo. Educación Matemática, 26(2), 69-109.

Rondero, C., \& Font, V. (2015). Articulación de la complejidad matemática de la media aritmética. Enseñanza de las Ciencias, 33(2), 29-49. https:/ / doi.org/10.5565/rev/ensciencias.1386

Sahin, Z., Erbas, A. K., \& Yenmez, A. A. (2015). Relational Understanding of the Derivative Concept through Mathematical Modeling: A Case Study. EURASIA Journal of Mathematics, Science E Technology Education, 11(1), 177-188. https:/ / doi.org/10.12973/eurasia.2015.1149a

Sánchez-Matamoros, G. Fernández, C., \& Llinares, S. (2015). Developing pre-service teachers' noticing of students' understanding of the derivative concept. International Journal of Science and Mathematics Education, 13(6), 1305-1329. https:// doi.org/10.1007/s10763-014-9544-y

Sánchez-Matamoros, G., García, M., \& Llinares, S. (2008). La comprensión de la derivada como objeto de investigación en didáctica de la matemática. Revista Latinoamericana de Matemática Educativa, 11(2), $267-296$.

Selden, J., Selden, A., \& Mason, A. (1994). Even good calculus students can't solve non-routine problems. In J. J. Kaput \& E. Dubinsky (Eds.), Research issues in undergraduate mathematics learning, MAA Notes 33 (pp. 19-26). Washington, D.C.: Mathematical Association of America.

Stewart, J. (2010). Calculus, 7th Edition. Brooks/Cole Cengage Learning, Mason.

Tall, D. (2013). How Humans Learn to Think Mathematically: Exploring the Three Worlds of Mathematics. Cambridge University Press.

Tall, D., \& Vinner, S. (1981). Concept image and concept definition in mathematics with particular reference to limits and continuity. Educational Studies in Mathematics, 12(2), 151-169. https:// doi.org/10.1007/BF00305619

Tiwari, T. K. (2007). Computer Graphics as an Instructional Aid in an Introductory Differential Calculus Course. International Electronic Journal of Mathematics Education, 2(1), 32-48.

Trigueros, M., \& Martínez-Planell, R. (2010). Geometrical representations in the learning of two-variable functions. Educational Studies in Mathematics, 73(1), 3-19. https:/ / doi.org/10.1007/s10649-009-9201-5

Zandieh M. (2000). A theoretical framework for analyzing students understanding of the concept of derivative. In E. Dubinsky, A. H. Schoenfeld \& J. Kaput, Research in Collegiate Mathematics Education. (Vol IV, pp.103-127). Providence, RI: American Mathematical Society.

\section{http://www.ejmste.com}

